\title{
PERANCANGAN SISTEM INFORMASI ADMINISTRASI SURAT DESA MENGGUNAKAN BASIS DATA MYSQL
}

\author{
Andria \\ Universitas PGRI Madiun; Jl Setia Budi No. 85, Madiun \\ Jurusan Sistem Informasi, Fakultas Teknik, UNIPMA, Madiun \\ Email : andria@unipma.ac.id
}

\begin{abstract}
Abstrak-Pengolahan data administrasi surat desa apabila dalam implementasinya masih menggunakan cara manual, maka informasi yang dibutuhkan memerlukan waktu yang relatif lama. Data administrasi surat yang sangat banyak juga memungkinkan terjadinya kekeliruan saat proses manajemen data. Berdasarkan permasalahan tersebut, dengan adanya perancangan sistem informasi administrasi surat desa secara terkompterisasi, diharapkan dapat memberikan kemudahan dalam penyampaian informasi dan mempermudah dalam proses manajemen data dengan lebih baik.
\end{abstract}

Kata kunci : Sistem Informasi, Basis Data, Administrasi Surat, MySQL

\section{PENDAHULUAN}

Pelayanan administrasi kependudukan berbasis web (online) merupakan suatu terobosan dalam rangka peningkatan kepuasan masyarakat akan kinerja pemerintah desa sekaligus optimalisasi teknologi di bidang informasi dan komunikasi yang mana dengan pemanfaatan teknologi ini masyarakat dapat dilayani kapanpun dan dimanapun. [1]

Proses administrasi surat masih menggunakan cara yang manual, seperti dengan melakukan pengisian formulir menggunakan media lembar kertas yang disediakan oleh perangkat desa, karena menggunakan cara manual tersebut yakni dengan tulisan tangan, maka memungkinkan perangkat desa kesulitan dalam membaca, serta banyaknya masyarakat yang mengurus surat akan memungkinkan terjadinya antrian yang menumpuk.

Berdasarkan permasalahan di atas maka perlu dikembangkan perancangan sistem informasi administrasi surat desa, sehingga diharapkan dalam proses pengolahan dan pengelolaan data dapat dimanajemen dengan lebih cepat, tepat, dan akurat dalam memenuhi kebutuhan data yang diperlukan serta mampu menunjang layanan terbaik yang diberikan kepada masyarakat dengan efisiensi dan efektivitas yang optimal.

\section{LANDASAN TEORI}

Konsep dasar sistem informasi

Suatu sistem dapat didefinisikan sebagai suatu himpunan atau kumpulan dari komponen, atau variabel yang terorganisir, saling berinteraksi, saling tergantung satu sama lain, dan terpadu. [2]

Sistem informasi merupakan sistem didalam suatu organisasi yang mempertemukan kebutuhan pengolahan transaksi yang mendukung fungsi operasi organisasi yang bersifat manajerial dengan kegiatan strategi dari suatu organisasi untuk dapat menyediakan kepada pihak luar berupa laporan yang diperlukan. [2]

Basis Data

Basis data merupakan komponen penting dalam sebuah sistem informasi modern. Sebagian besar sistem informasi menggunakan Relational Database Management System (RDBMS). [3] 
Sistem Basis Data

Database merupakan suatu kumpulan data terhubung (integrated) yang disimpan secara bersama pada suatu media, data disimpan dengan cara tertentu sehingga mudah untuk digunakan sehingga proses modifikasi data dapat dilakukan dengan mudah dan terkontrol. Database system mempunyai elemen penting yaitu:

1) Database sebagai inti dari sistem basis data

2) Program aplikasi untuk manajemen basis data

3) Perangkat keras sebagai penunjang operasi manajemen data

4) Brainware yang mempunyai peran penting dalam sistem tersebut [4]

Gambar dibawah ini menunjukkan levellevel yang ada dalam arsitektur sistem basis data.

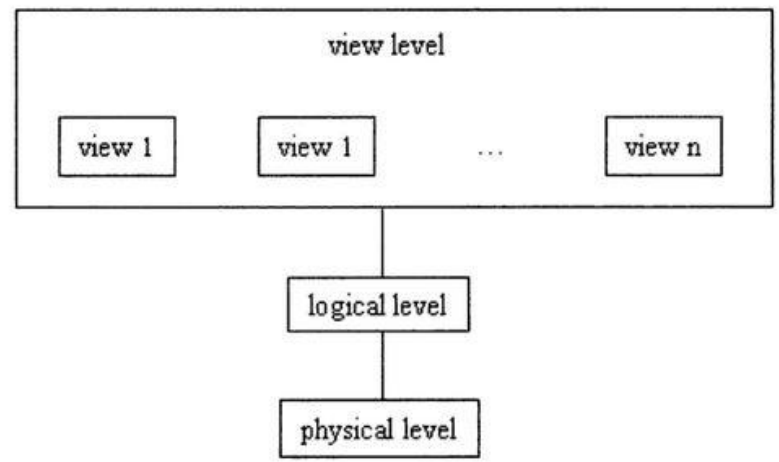

Gambar 1. Arsitektur Sistem Basis Data [7]

\section{Basis Data Terdistribusi}

Data yang digunakan secara bersama dan memiliki efisiensi dalam pengaksesan data harus diiringi dengan perkembangan sistem basis data yang disebut dengan basis data terdistribusi, yang dapat diakses dimana saja dan melakukan penyimpanan data di lokasi yang berbeda (Ramakrishnan, R. G., 2003).

Distribusi DBMS diharapkan dapat mengatasi sekumpulan permasalahan informasi. Terdapat 3 faktor yang yang dianjurkan untuk digunakan pada sistem basis data terdistribusi yaitu :

1. Fragmentasi : Sebuah relasi yang terbagi menjadi beberapa sub-sub relasi yang disebut dengan fragment, sehingga disebut juga distribusi.

2. Alokasi, setiap fragmen disimpan pada situs dengan distribusi yang optimal.

3. Replikasi, DDBMS dapat membuat suatu copy [8]

$M y S Q L$

Database MySQL merupakan sistem pengelolaan basis data $S Q L$ yang open source atau gratis dan bebas dikembangkan. [5]

\section{Entity Relationship Diagram (ERD)}

Entity relationship model merupakan suatu model data yang dikembangkan berdasarkan objek. ER_M digunakan untuk menjelaskan hubungan antar data dalam basis data kepada pemakai secara logik. ER_M digambarkan dalam bentuk diagram yang disebut dengan (ER_Diagram/ER_D) dengan menggunakan simbol-simbol grafis tertentu. (Edhy Sutanta, 2004:79) [6]

\section{RUMUSAN MASALAH}

Bagaimana merancang Sistem Informasi Administrasi Surat yang dapat memudahkan masyarakat dalam proses kepengurusan surat?

\section{METODE}

Perancangan Sistem Basis Data

Perancangan database difungsikan untuk menentukan struktur tabel dan relasi tabel yang akan diimplementasi ke dalam basis data MySQL. Adapun struktur tabel yang dirancang adalah seperti pada tabel 1 sampai dengan tabel 11.

Tabel 1. Table Administrator

\begin{tabular}{|c|c|c|c|c|}
\hline No & Field & Type & Size & $\begin{array}{c}\text { Keterang } \\
\text { an }\end{array}$ \\
\hline 1 & $\begin{array}{c}\text { usernam } \\
\text { e }\end{array}$ & varchar & 30 & \\
\hline 2 & password & varchar & 30 & \\
\hline
\end{tabular}

Tabel 2. Table Biodata 


\begin{tabular}{|c|c|c|c|c|}
\hline No & Field & Type & Size & $\begin{array}{c}\text { Keterang } \\
\text { an }\end{array}$ \\
\hline 1 & id_biodata & int & 5 & $\begin{array}{c}\text { Primary } \\
\text { Key }\end{array}$ \\
\hline 2 & nama & $\begin{array}{c}\text { varch } \\
\text { ar }\end{array}$ & 30 & \\
\hline 3 & nik & $\begin{array}{c}\text { varch } \\
\text { ar }\end{array}$ & 60 & \\
\hline 4 & no_telp & $\begin{array}{c}\text { varch } \\
\text { ar }\end{array}$ & 60 & \\
\hline 5 & email & $\begin{array}{c}\text { varch } \\
\text { ar }\end{array}$ & 30 & \\
\hline
\end{tabular}

Tabel 3. Table KK

\begin{tabular}{|c|c|c|c|c|}
\hline No & Field & Type & Size & $\begin{array}{c}\text { Keterang } \\
\text { an }\end{array}$ \\
\hline 1 & id_kk & int & 5 & $\begin{array}{c}\text { Primary } \\
\text { Key }\end{array}$ \\
\hline 2 & nama & $\begin{array}{c}\text { varch } \\
\text { ar }\end{array}$ & 30 & \\
\hline 3 & nik & $\begin{array}{c}\text { varch } \\
\text { ar }\end{array}$ & 60 & \\
\hline 4 & no_telp & $\begin{array}{c}\text { varch } \\
\text { ar }\end{array}$ & 60 & \\
\hline 5 & email & $\begin{array}{c}\text { varch } \\
\text { ar }\end{array}$ & 30 & \\
\hline 6 & alasan & $\begin{array}{c}\text { varch } \\
\text { ar }\end{array}$ & 20 & \\
\hline
\end{tabular}

\begin{tabular}{|c|c|c|c|c|}
\hline & & & & an \\
\hline 1 & id_nikah & int & 5 & $\begin{array}{c}\text { Primary } \\
\text { Key }\end{array}$ \\
\hline 2 & nama & $\begin{array}{l}\text { varch } \\
\text { ar }\end{array}$ & 30 & \\
\hline 3 & nik & $\begin{array}{c}\text { varch } \\
\text { ar }\end{array}$ & 60 & \\
\hline 4 & no_telp & $\begin{array}{l}\text { varch } \\
\text { ar }\end{array}$ & 60 & \\
\hline 5 & email & $\begin{array}{c}\text { varch } \\
\text { ar }\end{array}$ & 30 & \\
\hline 6 & $\begin{array}{c}\text { nama_pen } \\
\text { gantin }\end{array}$ & $\begin{array}{l}\text { varch } \\
\text { ar }\end{array}$ & 20 & \\
\hline 7 & $\begin{array}{c}\text { nama_aya } \\
\mathrm{h}\end{array}$ & $\begin{array}{l}\text { varch } \\
\text { ar }\end{array}$ & 60 & \\
\hline 8 & ttl & $\begin{array}{l}\text { varch } \\
\text { ar }\end{array}$ & 60 & \\
\hline 9 & wn & $\begin{array}{l}\text { varch } \\
\text { ar }\end{array}$ & 50 & \\
\hline 10 & agama & $\begin{array}{c}\text { varch } \\
\text { ar }\end{array}$ & 50 & \\
\hline 11 & $\mathrm{jk}$ & $\begin{array}{l}\text { varch } \\
\text { ar }\end{array}$ & 30 & \\
\hline 12 & pekerjaan & $\begin{array}{l}\text { varch } \\
\text { ar }\end{array}$ & 50 & \\
\hline 13 & alamat & $\begin{array}{l}\text { varch } \\
\text { ar }\end{array}$ & 60 & \\
\hline 14 & rtrw & $\begin{array}{l}\text { varch } \\
\text { ar }\end{array}$ & 50 & \\
\hline 15 & kec & $\begin{array}{l}\text { varch } \\
\text { ar }\end{array}$ & 50 & \\
\hline 16 & $\mathrm{kab}$ & $\begin{array}{c}\text { varch } \\
\text { ar }\end{array}$ & 50 & \\
\hline 17 & propinsi & $\begin{array}{l}\text { varch } \\
\text { ar }\end{array}$ & 50 & \\
\hline
\end{tabular}

Tabel 4. Table KTP

\begin{tabular}{|c|c|c|c|c|}
\hline No & Field & Type & Size & $\begin{array}{c}\text { Keterang } \\
\text { an }\end{array}$ \\
\hline 1 & id_ktp & int & 5 & $\begin{array}{c}\text { Primary } \\
\text { Key }\end{array}$ \\
\hline 2 & nama & $\begin{array}{c}\text { varch } \\
\text { ar }\end{array}$ & 30 & \\
\hline 3 & nik & $\begin{array}{c}\text { varch } \\
\text { ar }\end{array}$ & 60 & \\
\hline 4 & no_telp & $\begin{array}{c}\text { varch } \\
\text { ar }\end{array}$ & 60 & \\
\hline 5 & email & $\begin{array}{c}\text { varch } \\
\text { ar }\end{array}$ & 30 & \\
\hline 6 & jenis & $\begin{array}{c}\text { varch } \\
\text { ar }\end{array}$ & 20 & \\
\hline
\end{tabular}

Tabel 5. Table Nikah

\begin{tabular}{|l|l|l|l|l|}
\hline No & Field & Type & Size & Keterang \\
\hline
\end{tabular}

Tabel 6. Table Pengunduran

\begin{tabular}{|c|c|c|c|c|}
\hline No & Field & Type & Size & $\begin{array}{c}\text { Keterang } \\
\text { an }\end{array}$ \\
\hline 1 & $\begin{array}{c}\text { id_pengun } \\
\text { duran }\end{array}$ & int & 5 & $\begin{array}{c}\text { Primary } \\
\text { Key }\end{array}$ \\
\hline 2 & nama & $\begin{array}{c}\text { varch } \\
\text { ar }\end{array}$ & 30 & \\
\hline 3 & nik & $\begin{array}{c}\text { varch } \\
\text { ar }\end{array}$ & 60 & \\
\hline 4 & no_telp & $\begin{array}{c}\text { varch } \\
\text { ar }\end{array}$ & 60 & \\
\hline 5 & email & varch & 30 & \\
\hline
\end{tabular}




\begin{tabular}{|c|l|c|l|l|}
\hline & & ar & & \\
\hline 6 & keperluan & $\begin{array}{c}\text { varch } \\
\text { ar }\end{array}$ & 20 & \\
\hline 7 & keterangan & $\begin{array}{c}\text { varch } \\
\text { ar }\end{array}$ & 20 & \\
\hline
\end{tabular}

Tabel 7. Table SKCK

\begin{tabular}{|c|c|c|c|c|}
\hline No & Field & Type & Size & $\begin{array}{c}\text { Keterang } \\
\text { an }\end{array}$ \\
\hline 1 & id_skck & int & 5 & $\begin{array}{c}\text { Primary } \\
\text { Key }\end{array}$ \\
\hline 2 & nama & $\begin{array}{c}\text { varch } \\
\text { ar }\end{array}$ & 30 & \\
\hline 3 & nik & $\begin{array}{c}\text { varch } \\
\text { ar }\end{array}$ & 60 & \\
\hline 4 & no_telp & $\begin{array}{c}\text { varch } \\
\text { ar }\end{array}$ & 60 & \\
\hline 5 & email & $\begin{array}{c}\text { varch } \\
\text { ar }\end{array}$ & 30 & \\
\hline 6 & keperluan & $\begin{array}{c}\text { varch } \\
\text { ar }\end{array}$ & 20 & \\
\hline
\end{tabular}

\begin{tabular}{|c|c|c|l|l|}
\hline & & ar & & \\
\hline 4 & no_telp & $\begin{array}{c}\text { varch } \\
\text { ar }\end{array}$ & 60 & \\
\hline 5 & email & $\begin{array}{c}\text { varch } \\
\text { ar }\end{array}$ & 30 & \\
\hline 6 & keperluan & $\begin{array}{c}\text { varch } \\
\text { ar }\end{array}$ & 20 & \\
\hline
\end{tabular}

Tabel 10. Table Umum

\begin{tabular}{|c|c|c|c|c|}
\hline No & Field & Type & Size & $\begin{array}{c}\text { Keterang } \\
\text { an }\end{array}$ \\
\hline 1 & id_umum & int & 5 & $\begin{array}{c}\text { Primary } \\
\text { Key }\end{array}$ \\
\hline 2 & nama & $\begin{array}{c}\text { varch } \\
\text { ar }\end{array}$ & 30 & \\
\hline 3 & nik & $\begin{array}{c}\text { varch } \\
\text { ar }\end{array}$ & 60 & \\
\hline 4 & no_telp & $\begin{array}{c}\text { varch } \\
\text { ar }\end{array}$ & 60 & \\
\hline 5 & email & $\begin{array}{c}\text { varch } \\
\text { ar }\end{array}$ & 30 & \\
\hline 6 & keperluan & $\begin{array}{c}\text { varch } \\
\text { ar }\end{array}$ & 20 & \\
\hline
\end{tabular}

Tabel 8. Table Surat Keterangan

\begin{tabular}{|c|c|c|c|c|}
\hline No & Field & Type & Size & $\begin{array}{c}\text { Keterang } \\
\text { an }\end{array}$ \\
\hline 1 & id_sk & int & 5 & $\begin{array}{c}\text { Primary } \\
\text { Key }\end{array}$ \\
\hline 2 & nama & $\begin{array}{c}\text { varch } \\
\text { ar }\end{array}$ & 30 & \\
\hline 3 & nik & $\begin{array}{c}\text { varch } \\
\text { ar }\end{array}$ & 60 & \\
\hline 4 & no_telp & $\begin{array}{c}\text { varch } \\
\text { ar }\end{array}$ & 60 & \\
\hline 5 & email & $\begin{array}{c}\text { varch } \\
\text { ar }\end{array}$ & 30 & \\
\hline 6 & keperluan & $\begin{array}{c}\text { varch } \\
\text { ar }\end{array}$ & 20 & \\
\hline 7 & keterangan & $\begin{array}{c}\text { varch } \\
\text { ar }\end{array}$ & 20 & \\
\hline
\end{tabular}

Tabel 11. Table Usaha

\begin{tabular}{|c|c|c|c|c|}
\hline No & Field & Type & Size & $\begin{array}{c}\text { Keterang } \\
\text { an }\end{array}$ \\
\hline 1 & id_usaha & int & 5 & $\begin{array}{c}\text { Primary } \\
\text { Key }\end{array}$ \\
\hline 2 & nama & $\begin{array}{c}\text { varch } \\
\text { ar }\end{array}$ & 30 & \\
\hline 3 & nik & $\begin{array}{c}\text { varch } \\
\text { ar }\end{array}$ & 60 & \\
\hline 4 & no_telp & $\begin{array}{c}\text { varch } \\
\text { ar }\end{array}$ & 60 & \\
\hline 5 & email & $\begin{array}{c}\text { varch } \\
\text { ar }\end{array}$ & 30 & \\
\hline 6 & keperluan & $\begin{array}{c}\text { varch } \\
\text { ar }\end{array}$ & 20 & \\
\hline
\end{tabular}

Tabel 9. Table Tidak Mampu

\begin{tabular}{|c|c|c|c|c|}
\hline No & Field & Type & Size & $\begin{array}{c}\text { Keterang } \\
\text { an }\end{array}$ \\
\hline 1 & $\begin{array}{c}\text { id_tidakm } \\
\text { ampu }\end{array}$ & int & 5 & $\begin{array}{c}\text { Primary } \\
\text { Key }\end{array}$ \\
\hline 2 & nama & $\begin{array}{c}\text { varch } \\
\text { ar }\end{array}$ & 30 & \\
\hline 3 & nik & varch & 60 & \\
\hline
\end{tabular}

\section{Entitiy Relationship Diagram}

Entity Relationship Diagram (ERD) merupakan suatu model teknik pendekatan yang menyatakan atau menggambarkan hubungan suatu model. Diagram ER-D digunakan untuk menunjukan objek data (entity) dan hubungan (Relationship) yang ada pada entity lainnya. Hal yang harus 
diperhatikan yaitu tingkat hubungan atau kardinalitas apakah 1:1, 1:M atau M:N. Berikut ini adalah ERD yang didapat berdasarkan hasil proses yang menunjukkan setiap entity memiliki relational dengan entitiy lainnya dengan derajat kardinalitas tertentu:

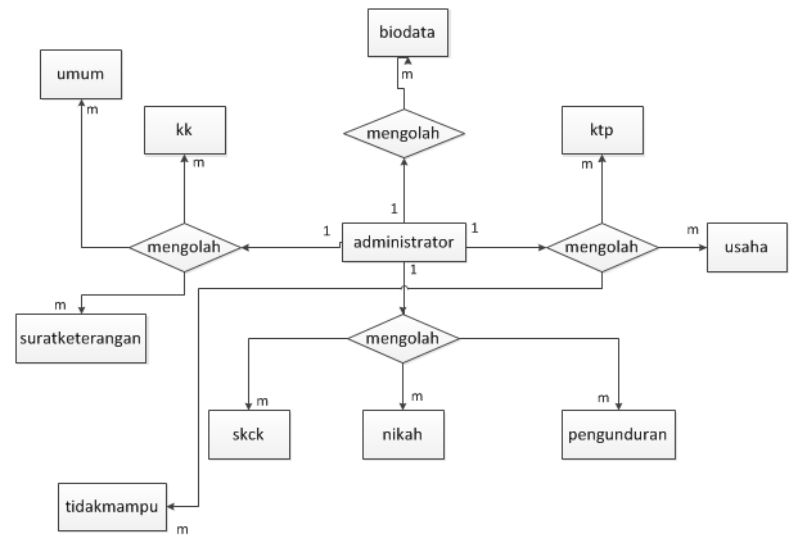

Gambar 1. Rancangan Entitiy Relationship Diagram Sistem Administrasi Surat

\section{Relasi Tabel}

Relasi tabel adalah hubungan antar tabel yang saling berkaitan dalam suatu basis data. Relasi tabel dapat saling berhubungan melalui index primary key dari tabel. Gambar 1 merupakan gambaran tentang relasi tabel sistem basis data administrasi surat desa.

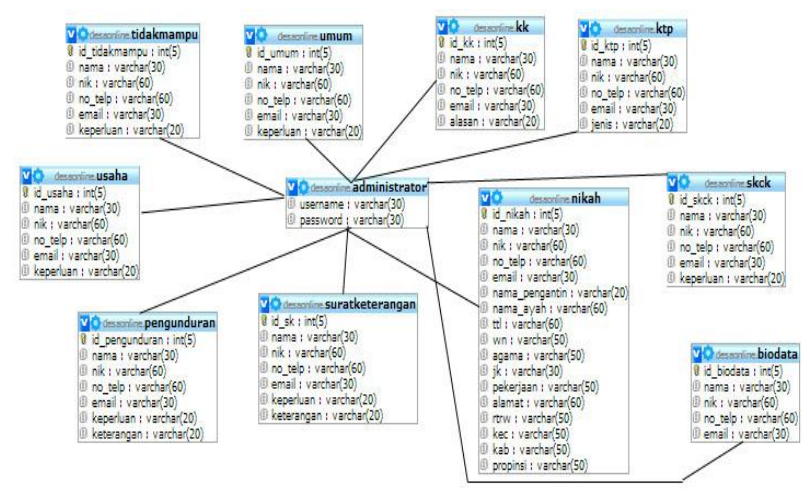

Gambar 2. Relasi Tabel

\section{KESIMPULAN}

Berdasarkan analisis yang dipaparkan, dapat disimpulkan bahwa dalam pengembangan sistem informasi pengolahan data administrasi surat desa dengan menggunakan basis data MySQL mampu menghasilkan pengolahan data yang lebih terstruktur yang didasarkan pada struktur tabel yang dirancang.

Dengan dibuatnya ERD maupun relasi tabel diharapkan akan memudahkan pengguna memahami alur kerja database sistem administrasi surat. Untuk pengembangan selanjutnya perlu dilengkapi dengan adanya fitur SMS Gateway yang dapat difungsikan untuk memberikan informasi berupa pengumuman terkait administrasi surat via mobile.

\section{DAFTAR PUSTAKA}

[1] S. Hidayatulloh and M. Cisde, "Sistem Pelayanan Administrasi Kependudukan Desa Candigatak Berbasis Web," Jurnal IT CIDA, vol. Vol. 1 No. 1, no. ISSN 2477- 8133, 2015.

[2] T. Sutabri, Konsep Sistem Informasi, Yogyakarta: CV. Andi Offset, 2012.

[3] S. Raharjo, "Constraint Basis Data Sebagai Fondasi Yang Kuat Dalam pengembangan Sistem Informasi," Prosiding Seminar Nasional Aplikasi Sains dan Teknologi (SNAST), no. ISSN 1979-911X, 2012.

[4] Worang and E. Sutanta, Sistem Basis Data', Yogyakarta: Graha Ilmu, 2004.

[5] Y. Kustihyaningsih and D. R. Anamisa, Pemrograman Basis Data Berbasis Web Menggunakan PHP \& MySQL, Yogyakarta: Graha Ilmu, 2011.

[6] R. Irawan and Sukadi, Pembuatan Sistem Penjualan Buku Berbasis Website Pada Toko Buku Pustaka Gemilang Utama Pacitan, 2013.

[7] Kusrini, Strategi Perancangan dan Pengelolaan Basis Data, Yogyakarta: CV. Andi Offset, 2007.

[8] P. D.P Silitonga, "Replikasi Basis Data Pada Sistem Pengolahan Data Akademik Universitas Katolik Santo Thomas," Jurnal Time, vol. Vol III No 1, no. ISSN 2337-3601, pp. 32-36, 2014. 